\title{
Pre-project Planning Process Study of Green Building Construction Projects in Thailand
}

\author{
Kritsada Khun-anod ${ }^{\mathrm{a}}$ and Charinee Limsawasd ${ }^{\mathrm{b}, *}$ \\ Department of Civil Engineering, Faculty of Engineering at Kamphaeng Saen, Kasetsart University, \\ Nakhon Pathom, 73140, Thailand \\ E-mail: aKritsada.khun@ku.th, bCharinee.1@ku.th (Corresponding author)
}

\begin{abstract}
Project effectiveness is a challenge in sustainable building construction projects. Lack of experience, knowledge, and skills in sustainable projects have been highlighted as the main barriers to using sophisticated and innovative techniques. Based on the literature, the pre-project planning effort directly influences a project's success. Nevertheless, the differences in planning efforts for green projects have not been fully determined, especially in Thailand, where sustainability just has only recently been considered in this context. This study investigated the status of pre-project planning for green building construction projects located in Thailand to promote sustainable construction. The analyses were performed based on two main objectives: (1) to compare the overall planning effort and (2) to address dissimilar planning factors between green and conventional projects. The concept of a project definition rating index (PDRI) was applied to evaluate the level of pre-project planning effort in 42 sample projects. An independent t-test was used for data analysis. The findings can contribute as the key strategies to facilitate the planning for sustainable buildings and help new practitioners to effectively allocate their constrained resources on significant project activities during the implementation of sustainable building construction.
\end{abstract}

Keywords: Pre-project planning, sustainable building, PDRI, independent t-test.

ENGINEERING JOURNAL Volume 23 Issue 6

Received 3 May 2019

Accepted 26 August 2019

Published 30 November 2019

Online at http://www.engj.org/

DOI:10.4186/ej.2019.23.6.67 


\section{Introduction}

There has been rapid development of the construction industry over the last century. Natural materials and resources have been in high demand for building construction. According to surveys, the building sector consumed almost $80 \%$ of natural materials [1] and another approximately $15 \%$ was water utilization [2]. The World Business Council for Sustainable Development reported that the building sector consumed around $40 \%$ of total energy usage [3]. Additionally, several studies have revealed the severity of environmental impacts due to construction activities, such as the mining process for material production, transporting materials using old hauling equipment, and disposing of unrecyclable waste materials from construction $[2$, 4-7].

The Basel Convention, the Kyoto Protocol Treaty, and the Rio Declaration were results from a global commitment to sustainable development to recover the natural environment [8]. These agreements led the construction industry to move forward in developing their businesses toward a healthier environment. The concept of green buildings has been recently adopted due to its significant long-term benefits, such as natural resource protection, indoor air quality improvement, and carbon dioxide emission reduction. As such, the construction industry has started to widely implement the sustainability concept.

There are several certified green building standards that have been established worldwide to certify the achievement of building sustainability. Among these standards, Leadership in Energy and Environmental Design (LEED) was developed by the US Green Building Council (USGBC) and has been widely implemented in many countries since 1993. It involves building sustainability assessment and results issuing a green certificate to a building based on seven aspects: (1) sustainable site, (2) water efficiency, (3) energy and atmosphere, (4) material and resources, (5) indoor environmental quality, (6) innovation in design, and (7) regional priority.

However, in order to obtain LEED certification, project planners are confronted with complicated requirements involving innovative and sophisticated technologies [9]. In addition, inexperienced and unskilled practitioners may cause negative project performance, both in terms of cost overrun and schedule delay [10]. Indeed, for the first implementation, most practitioners are not fully able to follow the LEED's requirements without specific guidelines. All the aforementioned statements imply that constructing sustainable buildings requires a large amount of effort in all project phases, especially the planning phase.

Pre-project planning is acknowledged as the most important process affecting project outcomes, as its productive plan can drive high project performance and success. Therefore, the pre-project planning process should be thoroughly performed to achieve the desired outcomes of the projects [11]. As a result, the building sector has started to develop a tool to support project planners. The project definition rating index (PDRI) emerged in 2000, with its purpose being to evaluate the sufficiency of the project implementation plan before an investment $[12,13]$. This tool has been validated and widely applied in many construction projects and research works $[14,15]$.

Although the advantages of sustainable projects have been widely recognized, most practitioners are more familiar with conventional project construction. Additionally, green projects have some characteristics in the planning process that are different from those in conventional projects. The literature shows that large effort is more likely in planning sustainable projects [14], confirming the need for a strong commitment from stakeholders and higher planning endeavor from all parties than is required for conventional projects [16].

Even though the different perspectives for planning green and conventional building construction projects have been studied $[14,17,18]$, they have not been thoroughly investigated with regard to current practice in Thailand. Therefore, this study aimed to investigate the planning effort for green building construction in Thailand using two main objectives: (1) to compare the level of planning effort and (2) to differentiate the major planning factors between green and conventional building construction projects. The findings highlighted the planning strategies for sustainable buildings that lead project planners to obtain an efficient project master plan. In addition, it contributes to practitioners in allocating their limited resources to significant project activities toward an implementation of sustainable building practice.

This paper is organized as follows. The next section introduces the concept of PDRI that was applied for designing a survey questionnaire. Then, the questionnaire and data collection are described, followed by the data analyses and results. The discussion section provides relevant information and the findings from other research studies that either support or conflict with the current results. The last section of this paper presents the conclusions along with the recommendations for further investigation. 


\section{Project Definition Rating Index (PDRI)}

The PDRI was developed as a pre-project planning evaluation tool by the Construction Industry Institute (CII) in 2000. The PDRI aims to evaluate the sufficiency of the project scope definition during the preproject planning phase to assist a front-end planning (FEP) team in developing a plan and obtaining a pleasant project status. The PDRI requires a great deal of coordination between the owner and the FEP to intensively develop and improve the project plan.

Figure 1 demonstrates all phases in a construction project, consisting of the pre-project planning, detailed design, construction, commissioning and startup, operation, and demolition phases. The pre-project planning phase can be categorized into three stages: planning for the feasibility study, conceptual design, and detailed scope definition. To develop the PDRI, the CII gathered all necessary planning factors from real practices, consisting of 3 sections, 11 categories, and 64 elements [12,13]. The three sections consist of: (1) basis of project decision, (2) basis of design, and (3) execution approach, in which each section is suggested to apply at different stages of the pre-project planning phase.

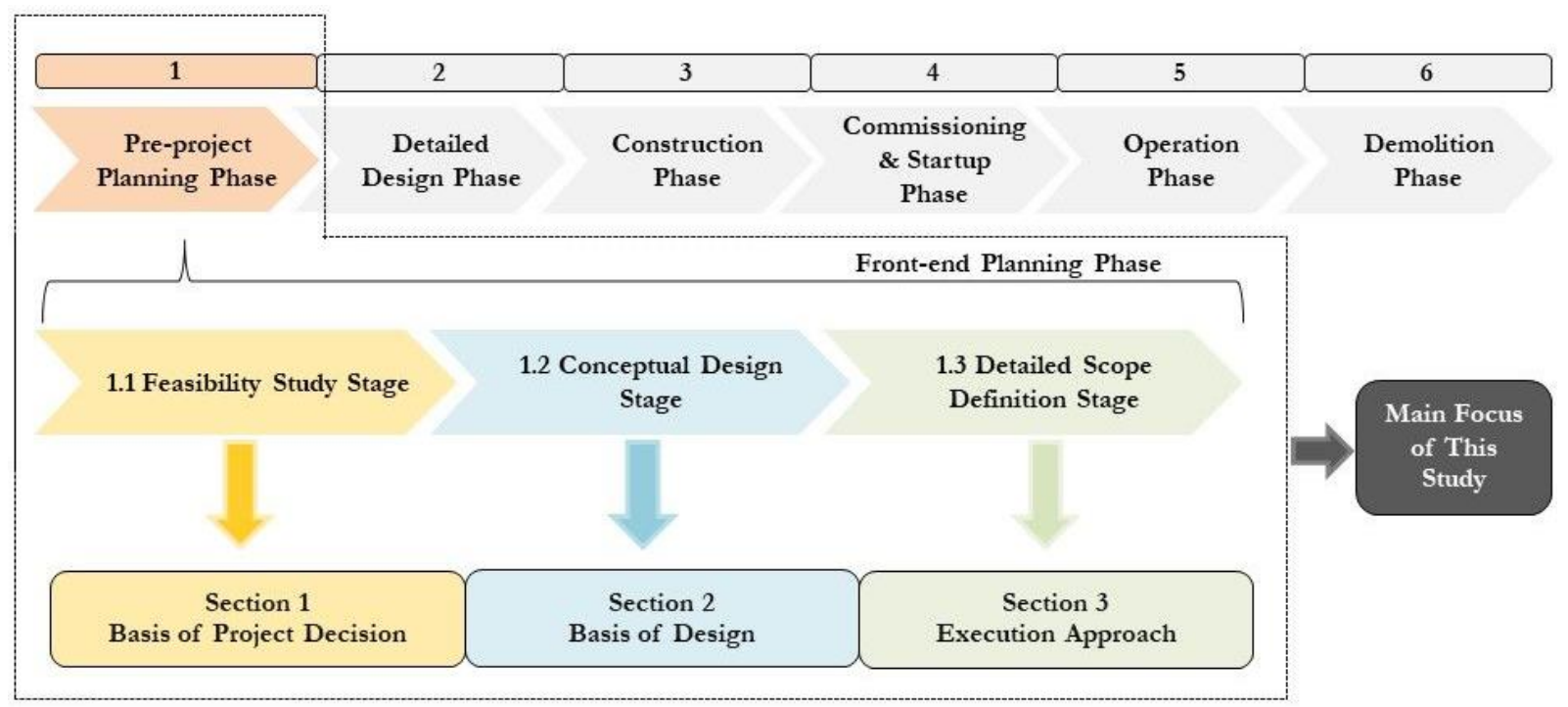

Fig. 1. Construction Project Phases and Appropriate Timing for PDRI Implementation.

Figure 2, Section 1 (Basis of project decision) highlights the feasibility study of the project before an investment by considering three categories: (A) business strategy, (B) owner philosophies, and (C) project requirements. This section integrates the feasibility study and all risk factors to support the owner's decision and ensure the possibility of achieving all the desired objectives of project investment. Section 2 (Basis of design) considers the conceptual design as per the owner's requirements by considering four categories: (D) building project design parameter, (E) site information, (F) building programing, and (G) equipment. The owner is required to place all requirements, allowing the FEP to be aware of which dimensions should be concerned with the project design. This section supports the FEP to plan the conceptual design under a variety of owner's limitations. Section 3 (Execution approach) focuses on the working process of the project construction regarding four categories: $(\mathrm{H})$ procurement strategy, $(\mathrm{J})$ deliverables, $(\mathrm{K})$ project control, and (L) project execution plan. The FEP needs to preliminarily initiate the plan for construction, subject to the limited time and budget. The explanation of each category is given as follows:

Category A (Business strategy) supports the owner and FEP in setting up the project master plan for business achievement. This category directs the owner and FEP to ascertain whether the project investment can be profitable. Category B (Owner's philosophies) assists the owner to decide which points should be concerned to confirm the reliability on the functional usage of the building for the end users. Category $\mathrm{C}$ (Project requirements) helps the owner to define all requirements, which benefits both the owner and the FEP in underlining important points for planning the projects. Category D (Site information) supports the FEP in fully investigating the construction site to obtain all necessary information for the project design. Category E (Building programming) requires the FEP to allocate the area and program the building construction to support the project design. Category $\mathrm{F}$ (Building/project design parameters) guides the FEP 
to develop the project design related to the architectural, structural, mechanical, and electrical aspects. Category G (Equipment) assists the FEP in terms of the equipment selection consideration, by focusing on the equipment location and utility requirement to facilitate an effective performance. Category $\mathrm{H}$ (Procurement strategy) supports the FEP to properly procure and manage the timing for the materials and equipment delivered to the construction site. Category J (Deliverables) supports the FEP to obtain all important documents that are necessary for the building construction project. Category K (Project control) assists the FEP to control the quality of the project under the time and budget constraints. Category L (Project execution plan) requires the FEP to state the execution plan that every party must comply with to assure accomplishment of the project goals.

\begin{tabular}{|c|c|c|c|c|c|c|c|c|}
\hline SECTION - & \multicolumn{8}{|c|}{ Section 1 Basis of Project Decision } \\
\hline CATEGORY - & \multicolumn{2}{|c|}{ Category A. Business Strategy } & \multicolumn{3}{|c|}{ Category B. Owner Philosophies } & \multicolumn{3}{|c|}{ Category C. Project Requirements } \\
\hline \multirow[t]{7}{*}{ ELEMENT $\longrightarrow$} & $\begin{array}{l}\text { A1. Building Use Requirements } \\
\text { A2. Business Justification } \\
\text { A3. Business Plan } \\
\text { A4. Economic Analysis } \\
\text { A5. Facility Requirements } \\
\text { A6. Future Expansion/Alteration } \\
\text { A7. Site Selection Considerations } \\
\text { A8. Project Objectives Statement }\end{array}$ & & $\begin{array}{l}\text { B1. Reliability Philos } \\
\text { B2. Maintenance Phi } \\
\text { B3. Operating Philos } \\
\text { B4. Design Philosoph }\end{array}$ & $\begin{array}{l}\text { phy } \\
\text { osophy } \\
\text { phy } \\
\text { y }\end{array}$ & & $\begin{array}{l}\text { C1. } \\
\text { C2. } \\
\text { C3. } \\
\text { C4. } \\
\text { C5. } \\
\text { C6. }\end{array}$ & $\begin{array}{l}\text { Value-An } \\
\text { Project D } \\
\text { Evaluatio } \\
\text { Scope of } \\
\text { Project S } \\
\text { Project C }\end{array}$ & $\begin{array}{l}\text { lysis Process } \\
\text { esign Criteria } \\
\text { of Existing Facilities } \\
\text { Work Overview } \\
\text { hedule } \\
\text { st Estimate }\end{array}$ \\
\hline & \multicolumn{8}{|c|}{ Section 2 Basis of Project Design } \\
\hline & Category D. Site Information & \multicolumn{3}{|c|}{ Category E. Building Programming } & \multicolumn{3}{|c|}{$\frac{\text { Category F. Building/Project }}{\text { Design parameters }}$} & Category G. Equipment \\
\hline & $\begin{array}{l}\text { D1. Site Layout } \\
\text { D2. Site Surveys } \\
\text { D3. Civil/Geotechnical Informat } \\
\text { D4. Governing Regulatory } \\
\text { Requirements } \\
\text { D5. Environmental Assessment } \\
\text { D6. Utility Sources with Supply } \\
\text { Conditions } \\
\text { D7. Site Life Safety Consideration } \\
\text { D8. Special Water and Waste } \\
\text { Treatment }\end{array}$ & \multicolumn{3}{|c|}{\begin{tabular}{||l|} 
E1. Program Statement \\
E2. Building Summary Space List \\
E3. Overall Adjacency Diagrams \\
E4. Stacking Diagrams \\
E5. Growth and Phased Development \\
E6. Circulation and Open Space \\
$\quad$ Requirements \\
E7. Functional Relationship Diagrams \\
E8. Loading/Unloading/Storage \\
E9. Transportation Requirements \\
E10. Building Finishes \\
E11. Room Data Sheets \\
E12. Furnishings, Equipment, \\
\& Built-Ins \\
E13. Window Treatment Considerations
\end{tabular}} & \multicolumn{3}{|c|}{$\begin{array}{l}\text { F1. Civil/Site Design } \\
\text { F2. Architectural Design } \\
\text { F3. Structural Design } \\
\text { F4. Mechanical Design } \\
\text { F5. Electrical Design } \\
\text { F6. Building Life Safety } \\
\text { F7. Constructability } \\
\quad \text { Analysis } \\
\text { F8. Technological } \\
\quad \text { Sophistication }\end{array}$} & $\begin{array}{l}\text { G1. Equipment List } \\
\text { G2. Equipment Location } \\
\text { Drawings } \\
\text { G3. Equipment Utility } \\
\text { Requirements }\end{array}$ \\
\hline & \multicolumn{8}{|c|}{ Section 3 Execution Approach } \\
\hline & $\begin{array}{c}\text { Category } \\
\text { H. Procurement Strategy }\end{array}$ & & Category J. Deliverables & Categor & ry K. Proj & trol & Catego & y L. Project Execution Plan \\
\hline & $\begin{array}{l}\text { H1. Identify Long Lead/Critical } \\
\text { Equipment and Materials } \\
\text { H2. Procurement Procedures } \\
\text { and Plans }\end{array}$ & & $\begin{array}{l}\text { CADD/Model Requirements } \\
\text { Documentation/Deliverables }\end{array}$ & $\begin{array}{l}\text { K1. Proje } \\
\text { K2. Proje } \\
\text { K3. Proje } \\
\text { Requ } \\
\text { K4. Risk } \\
\text { K5. Safet }\end{array}$ & $\begin{array}{l}\text { ct Quality } \\
\text { ect Cost C } \\
\text { ect Schedu } \\
\text { iirements } \\
\text { Managen } \\
\text { y Procedu }\end{array}$ & & $\begin{array}{l}\text { L1. Proj } \\
\text { L2. Ow1 } \\
\text { L3. Proj } \\
\text { L4. Des } \\
\text { App } \\
\text { L5. Sub } \\
\text { Rec }\end{array}$ & $\begin{array}{l}\text { ct Organization } \\
\text { er Approval Requirements } \\
\text { ct Delivery Method } \\
\text { gn/Construction Plan \& } \\
\text { oach } \\
\text { tantial Completion } \\
\text { iirements }\end{array}$ \\
\hline
\end{tabular}

Fig. 2. PDRI Details -3 Sections with 11 Categories and 64 Elements.

The relevant criteria are identified as the elements under each category, as demonstrated in Fig. 2. Each planning element provides detailed checklists for evaluating the level of the pre-project planning effort in a determined project. The detailed checklists are developed according to the professional experience among 69 participants (30 project engineers, 31 architects, and eight other professionals) [19]. As exemplified in Fig. 3, Element A2 (Business justification) contains six checklist items: need date, target consumer, level of amenities, location, sustainability consideration, and building utilization justification. Those detailed checklists are designed to be subjectively evaluated by the stakeholders/project planners in terms of the definition level to represent the planning effort. A lower value of the definition level refers to better performance in project planning, while a higher number represents a worse planning effort. The definition level is designed to help the planning team to underline which elements are vulnerable and could negatively impact project success. The detailed checklists for the other elements can be accessed in [19]. 


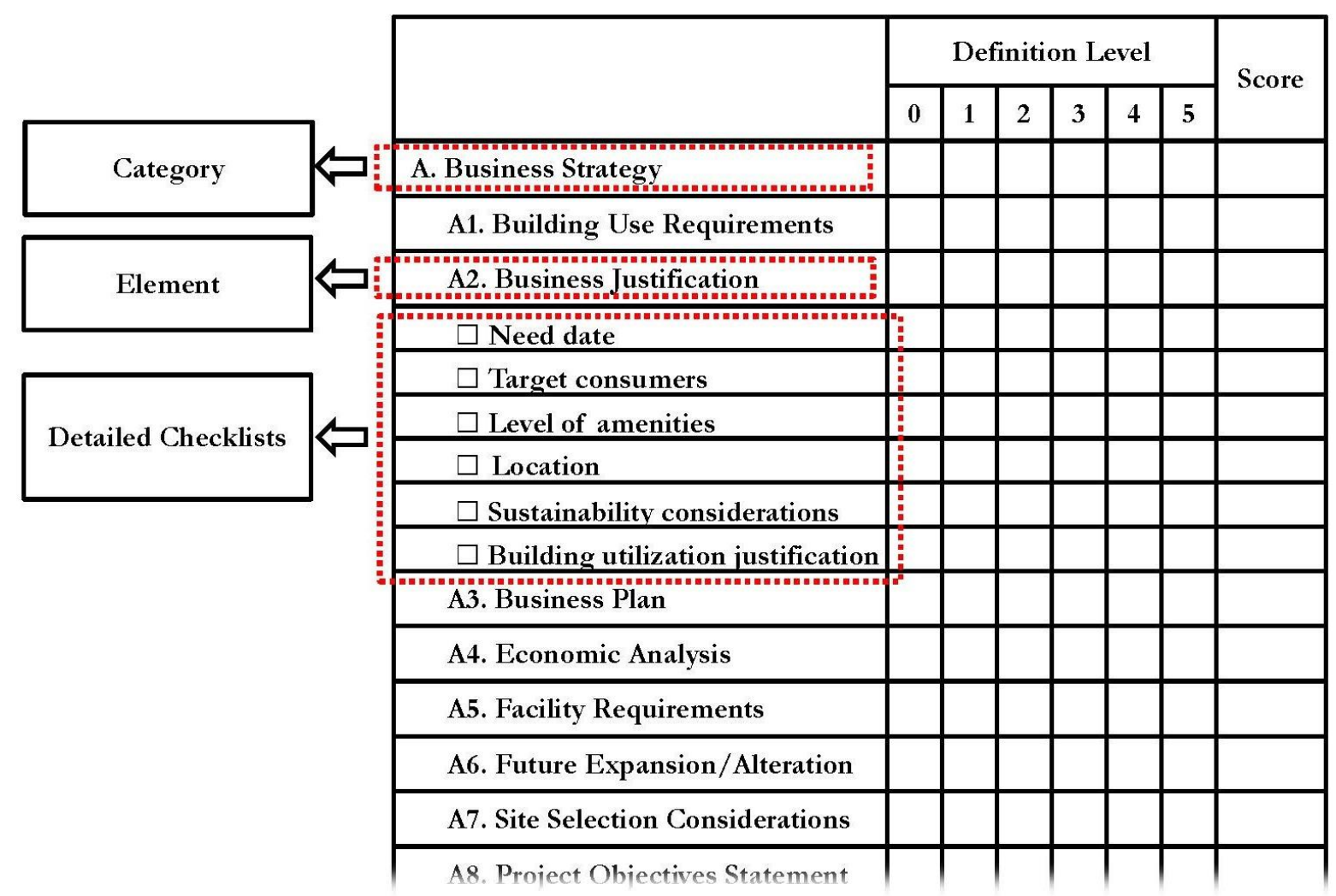

Remark: $0=$ Not applicable, $1=$ Complete Definition, $2=$ Minor Deficiencies, 3 = Some Deficiencies, 4 = Major Deficiencies, 5 = Incomplete Definition

Fig. 3. Example - Detailed Checklists and Concept for Evaluating Level of Planning Effort.

As previously explained, the PDRI's theoretical concepts generally guide involved parties in how to plan and evaluate the pre-project planning effort. To apply the PDRI to this study, a survey questionnaire was selected as the tool to collect the planning data. Explanations of how the questionnaire was established and the data were collected are given in the next section.

\section{Questionnaire and Data Collection}

Two main processes were performed to develop a questionnaire: (1) questionnaire design and (2) questionnaire validation. The survey questionnaire was developed based on the PDRI detailed checklist under the objectives of practicality and simplicity with the easy-to-understand questionnaire format. The clear description of the rating evaluation was also provided in terms of the definition level scaling from $0-5$ to address the bias and subjectivity issues, as follows: 0 represents an inapplicability of the considering checklist on the construction project; 1 represents an observation of the excellent plan with the completed definition; 2 represents an effective plan with some minor deficiencies; 3 represents an adequate plan with some possible deficiencies; 4 represents an insufficiency in the project plan with major deficiencies; and 5 represents a poor and incompletion on the defining plan. The designed questionnaire was later validated by the experienced specialists in academic and construction industry areas to guarantee an appropriateness, capability, and sufficiency of the questionnaire before actual data collection [20,21].

Figures 4, 5, and 6 describe three basic steps of how to evaluate the level of pre-project planning effort at the element, category, and project level, respectively. First, the level of pre-project planning effort is calculated based on detailed checklists. The score given for the definition level is averaged and identified as the level of pre-project planning effort for each element. For example, Element A2 was referred to under six checklist items, in which the scores for each item are averaged to represent the level of pre-project planning effort under the element (a value of 2.00 for Step 1 in Fig. 4). However, a score could be zero and, in such a 
case, it would not be used in the element level score calculation, as that checklist item was not considered to be applicable to the project. All elements are calculated using this approach.

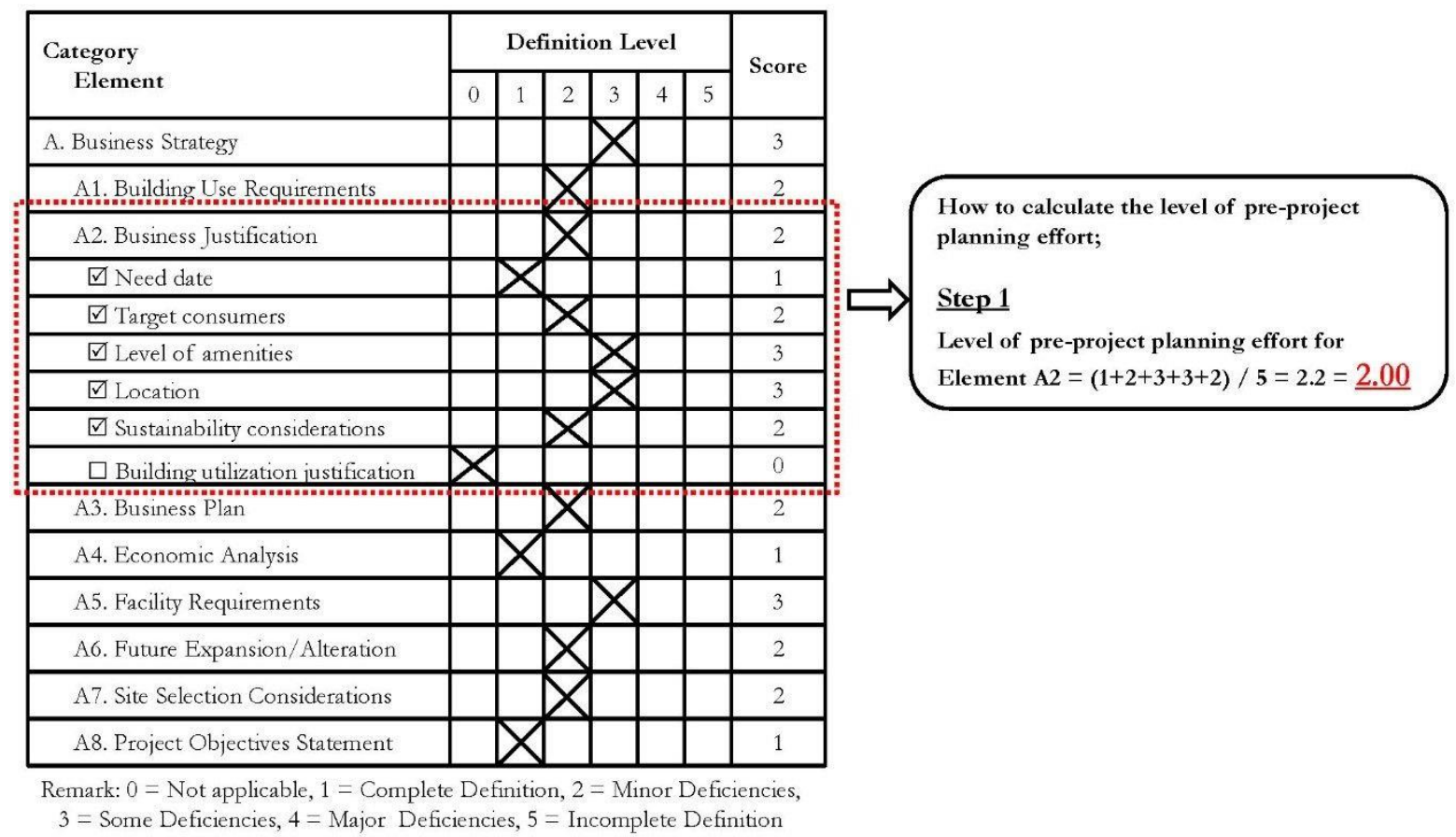

Fig. 4. Example of how to Calculate Level of Pre-project Planning Effort for Element.

Second, the level of pre-project planning effort at the category level is then calculated by considering an average value among all relevant checklist items. For example, the pre-project planning effort for Category A is averaged based on Element A1-A8, giving the category level effort at 2.00 (See Step 2 in Fig. 5). The same approach was also applied for Categories B to J.

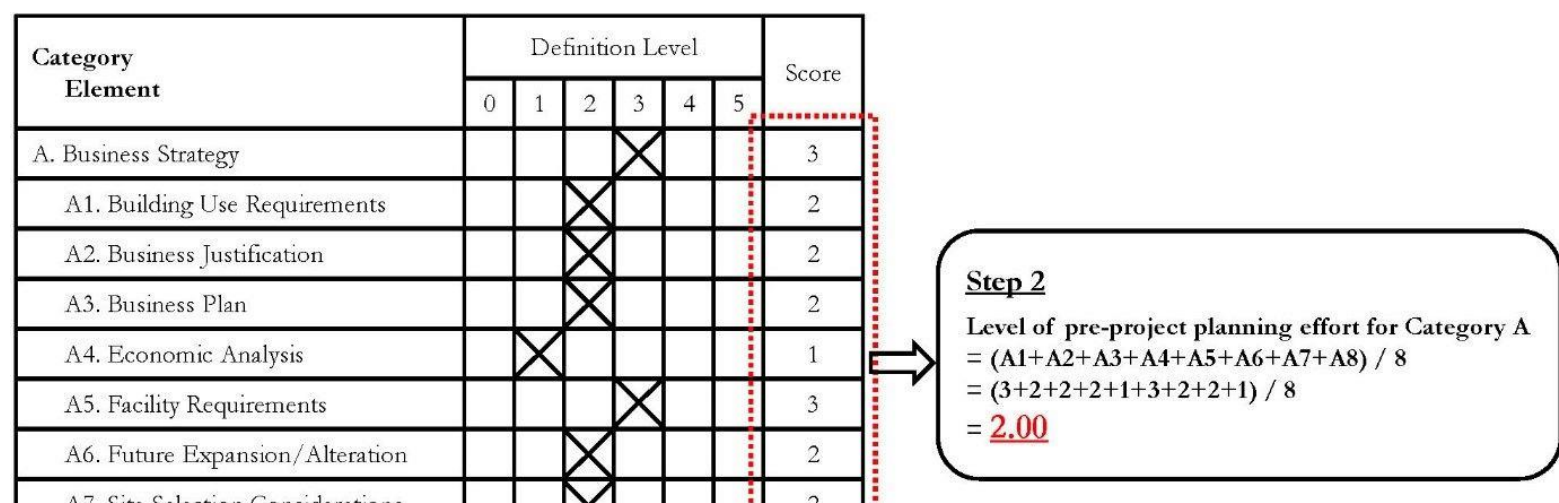

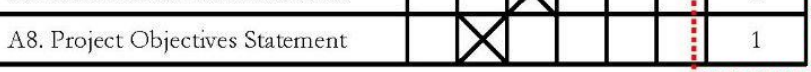

Remark: $0=$ Not applicable, 1 = Complete Definition, $2=$ Minor Deficiencies,

3 = Some Deficiencies, 4 = Major Deficiencies, 5 = Incomplete Definition

Fig. 5. Example of How to Calculate Level of Pre-project Planning Effort for Category.

After that, the overall level of pre-project planning effort for a project is averaged based on the effort scores calculated for all categories. Figure 6 shows the overall level for the example project is equal to 2.27, representing mediocre pre-project planning effort. 


\begin{tabular}{|c|c|c|c|c|c|c|c|c|c|}
\hline \multicolumn{8}{|c|}{ Questionnaire } & \multirow{7}{*}{ 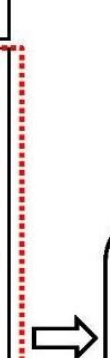 } & \\
\hline Section I & & & Enitic & on Le & & ! & Score & & \multirow{8}{*}{$\begin{array}{l}\underline{\text { Step } 3} \\
\text { Overall of Level of pre-project planning } \\
\text { effort for a project } \\
=(\mathrm{A}+\mathrm{B}+\mathrm{C}+\mathrm{D}+\mathrm{E}+\mathrm{F}+\mathrm{G}+\mathrm{H}+\mathrm{J}+\mathrm{K}+\mathrm{L}) / 11 \\
=(2+3+3+4+3+2+1+2+2+1+2) / 11=\underline{2.27}\end{array}$} \\
\hline A. Business Strategy & 0 & 1 & 2 & 3 & 4 & 5 & 2 & & \\
\hline B. Owner Philosophies & 0 & 1 & 2 & 3 & 4 & 5 & 3 & & \\
\hline C. Project Requirements & 0 & 1 & 2 & 3 & 4 & 5 & 3 & & \\
\hline Section II & \multicolumn{6}{|c|}{ Definition Level } & Score & & \\
\hline D. Site Information & 0 & 1 & 2 & 3 & 4 & 5 & 4 & & \\
\hline E. Building Programming & 0 & 1 & 2 & 3 & 4 & 5 & 3 & \multirow{2}{*}{ 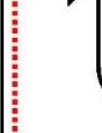 } & \\
\hline F. Building/Project Design Parameters & 0 & 1 & 2 & 3 & 4 & 5 & 2 & & \\
\hline G. Equipment & 0 & 1 & 2 & 3 & 4 & 5 & 1 & & \\
\hline Section III & \multicolumn{6}{|c|}{ Definition Level } & Score & & \\
\hline H. Procurement Strategy & 0 & 1 & 2 & 3 & 4 & 5 & 2 & & \\
\hline J. Deliverables & 0 & 1 & 2 & 3 & 4 & 5 & 2 & & \\
\hline K. Project Control & 0 & 1 & 2 & 3 & 4 & 5 & 1 & & \\
\hline L. Project Execution Plan & 0 & 1 & 2 & 3 & 4 & 5 & 2 & & \\
\hline
\end{tabular}

Fig. 6. How to Evaluate Overall Level of Pre-project Planning Effort for Project.

It is noteworthy to provide a further explanation of data collection on three major aspects: (1) survey sampling, (2) respondent's qualification, and (3) response rate. First, the green projects' populations were gathered from the official websites of the USGBC and the Thai's Rating of Energy and Environmental Sustainability (TREES). The data and information of all certified green buildings were recorded for future contact. Because of the limited number of green buildings, this study therefore decided to consider the buildings from both the LEED and TREES standards, as these two standards have been commonly accepted among stakeholders in the construction industry. The list of accessible conventional buildings was obtained from renovation and construction companies in Thailand. Then, 41 green and 40 conventional buildings were contacted. To classify the sample projects, the buildings with a green certificate were classified into the green sample group, while the buildings without certification were classified into the conventional sample group.

Second, the authors had to ensure whether the respondents could provide the reliable and accountable information. All the respondents then verified their qualification to ensure their ability to answer the questionnaire. In this study, the respondents had to be experienced in construction projects as a project owner, front-end-planning team, or owner representative, deeply involved in the planning process.

Third, there was $51 \%$ response rate for green projects (12 new-constructed and 9 renovation projects) and a $53 \%$ response rate for conventional projects ( 12 new-constructed and 9 renovation projects). The rest of population either did not respond or voluntarily disclose the project information due to the confidentiality issue. Moreover, the authors found that several projects had hired the outsource consultant companies for planning who were unavailable to participate the questionnaire at the time of data collection.

In summary, this study developed the questionnaire based on the PDRI requirements. The description of the evaluation was also provided to the respondents in order to address the issues of bias and subjectivity. Then, the developed questionnaire was evaluated by the specialists to validate the capability and performance of the designed questionnaire [22]. The survey was conducted on two sample groups: (1) new-constructed and (2) renovation projects. The data were gathered from 42 building projects in Thailand, which include 24 new-constructed projects (12 green and 12 conventional projects) and 18 renovation projects ( 9 green and 9 conventional projects).

\section{Data Analyses and Results}

The analyses were performed on two main groups of samples: (1) new-constructed projects and (2) renovation projects. An independent t-test was conducted to investigate two main issues: (1) to compare the level of pre-project planning effort and (2) to differentiate the major planning factors between green and conventional building construction projects. 
First, to compare the overall level of the pre-project planning efforts, the hypothesis was constructed that green projects tend to have a higher pre-project planning effort than conventional projects. Each sample group requires two types of variable, namely the project type as an independent variable and the overall level of the pre-project planning effort as a dependent variable.

The normality test was performed using the Shapiro-Wilk test and a normal Q-Q plot for the samples. Theoretically, the Shapiro-Wilk test is applied when 3-2,000 samples are collected. In this study, the p-values for green and conventional projects were 0.926 and 0.719 for the new projects and 0.050 and 0.135 for the renovation projects. At the $95 \%$ confidence level, these confirmed that each sample group was normally distributed and was representative of the respective populations [23-25]. The normal Q-Q plots for all comparison analyses were also tested, as shown in Fig. 7, where the plot illustrates a 45-degree trend line that satisfies normality.
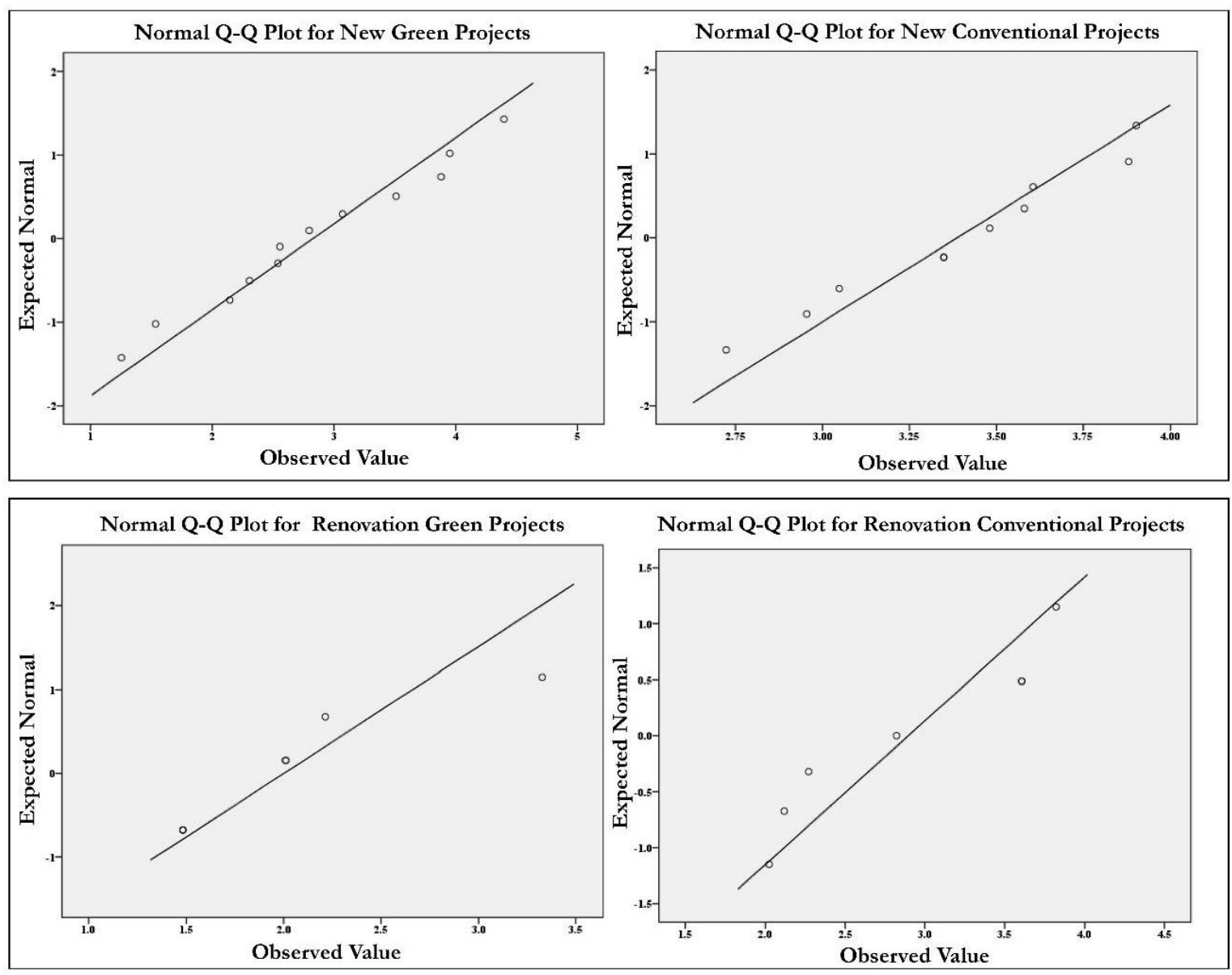

Fig. 7. Normal Q-Q Plot for Planning Effort for Two Sample Groups.

The mean values for green and conventional projects were 2.829 and 3.387 for the new projects and 2.001 and 2.896 for the renovation projects. As previously stated, a lower value reflects better performance during the planning process. Similar for all two sample groups, the mean values of the green projects were less than for the conventional ones, indicating that the green projects tended to have a higher planning endeavor than the conventional projects.

The independent t-test was then performed to compare the mean value of the overall level of pre-project planning effort. The p-values were 0.044 and 0.020 for the new and renovation projects, reflecting a significant difference at the $95 \%$ confidence level for each pair of sample groups, and confirming a higher effort during the pre-project planning process in green projects than conventional projects.

Second, the dissimilar planning factors were addressed according to 64 PDRI elements to compare the level of pre-project planning effort per element between the green and conventional projects using an independent $\mathrm{t}$-test. The result showed that the different planning factors for the new projects were significant 
for nine elements, as shown in Fig. 8. These factors were: Elements D4 (Governing regulatory requirements), E2 (Building summary space list), E3 (Overall adjacency diagrams), E4 (Stacking diagrams), E10 (Building finishes), E12 (Furnishings, equipment and built-ins), E13 (Window treatment considerations), F2 (Architectural design), and F3 (Structural design).

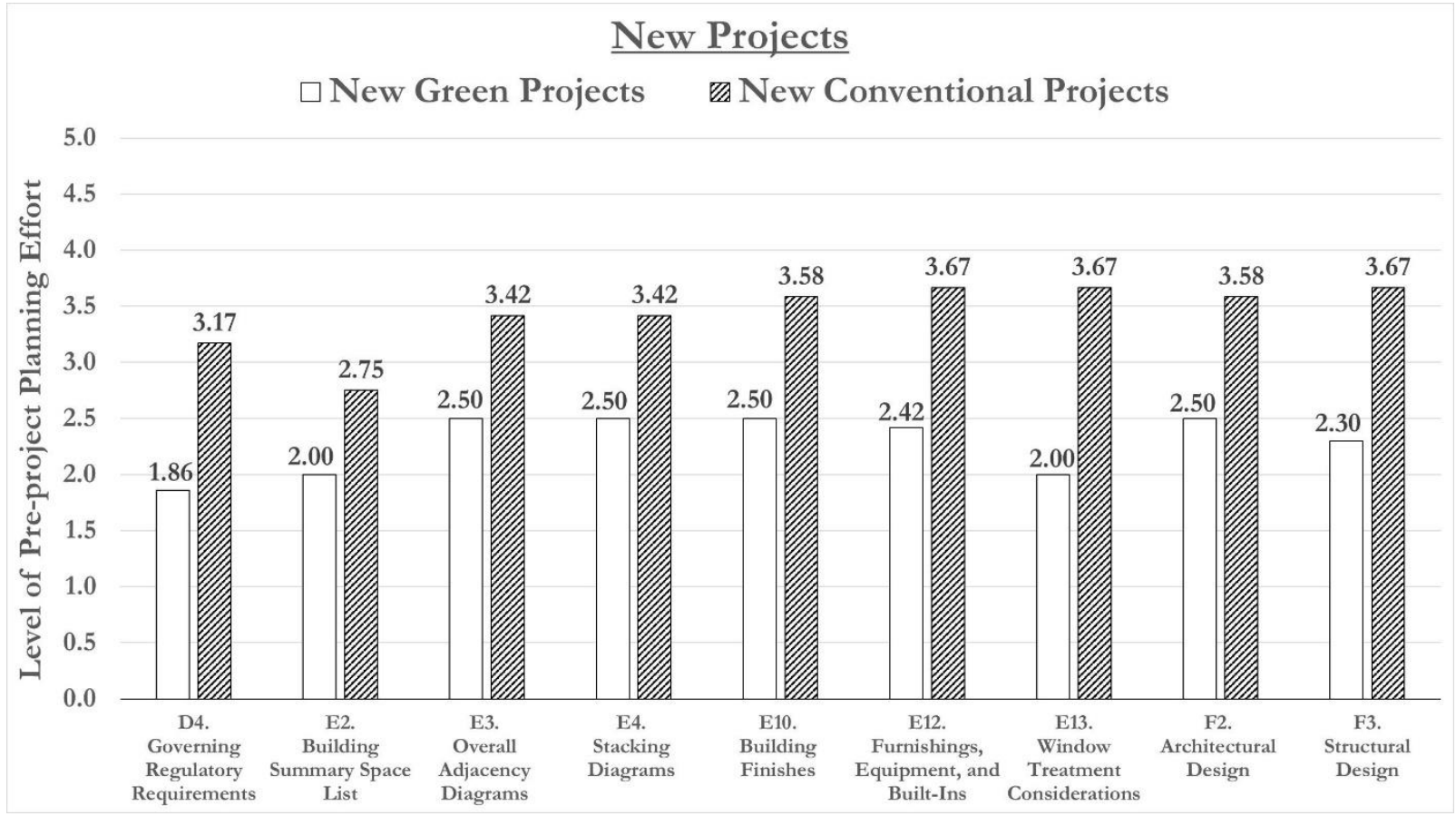

Fig. 8. Different Major Planning Factors for New Projects.

For the renovation projects, Fig. 9 specifies six different planning elements: Elements C1 (Value-analysis process), D5 (Environmental assessment), E12 (Furnishings, equipment and built-ins), E13 (Window treatment considerations), F4 (Mechanical design), and G3 (Equipment utility requirements).

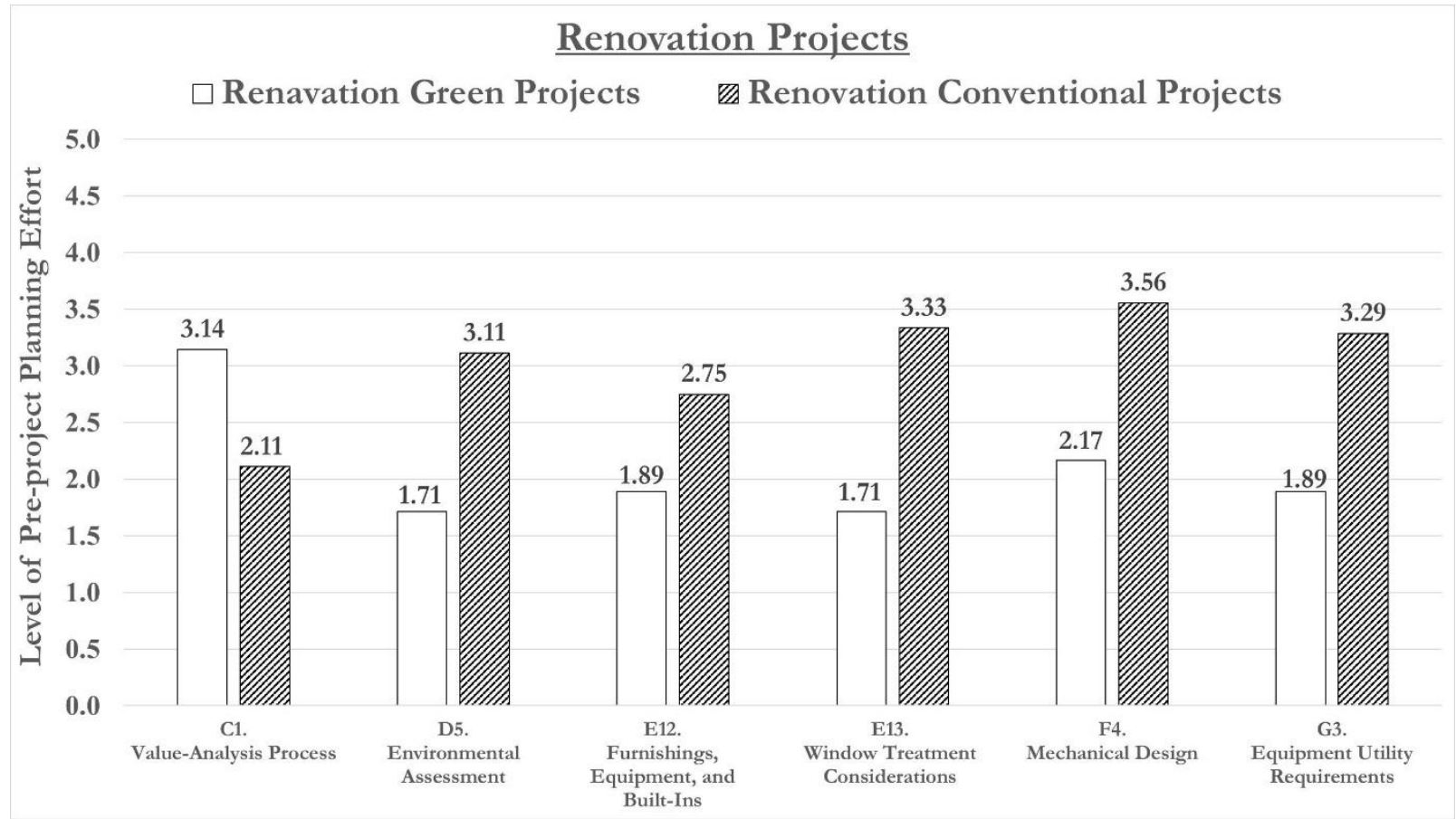

Fig. 9. Different Major Planning Factors for Renovation Projects. 


\section{Discussion}

First, the comparison of the pre-project planning effort showed meaningful evidence confirming that the green projects required greater planning than the conventional projects. Second, different planning factors were identified for both main parts according to Objective 2. This section discusses the results based on the dimension of the LEED criteria. The discussion is separated based on the two main groups of projects, newconstructed and renovation projects.

(1) New-constructed project

This part describes the nine elements of the different planning factors between green and conventional projects. Table 1 provides the matching results with the LEED requirements. The explanation of how each element correlates to the LEED standard is provided after.

Table 1. Matching Results with the LEED Requirements for New Projects.

\begin{tabular}{|c|c|c|c|c|c|c|c|}
\hline \multirow[b]{2}{*}{$\begin{array}{c}\text { Element } \\
\text { (New Projects) }\end{array}$} & \multicolumn{7}{|c|}{ LEED Requirements } \\
\hline & 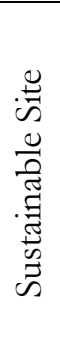 & 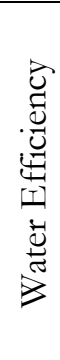 & 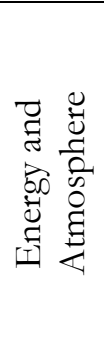 & 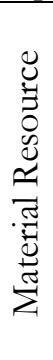 & 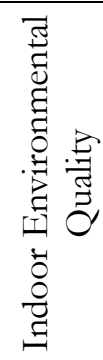 & 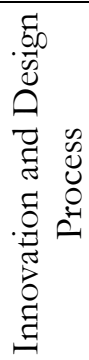 & 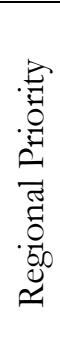 \\
\hline $\begin{array}{l}\text { D4. Governing regulatory } \\
\text { requirements }\end{array}$ & $\checkmark$ & & & & & $\checkmark$ & \\
\hline $\begin{array}{l}\text { E2. Building summary space } \\
\text { list }\end{array}$ & $\checkmark$ & $\checkmark$ & & & $\checkmark$ & $\checkmark$ & $\checkmark$ \\
\hline $\begin{array}{l}\text { E3. Overall adjacency } \\
\text { diagrams }\end{array}$ & $\checkmark$ & $\checkmark$ & & & $\checkmark$ & $\checkmark$ & $\checkmark$ \\
\hline E4. Stacking diagrams & & & & & & $\checkmark$ & \\
\hline E10. Building finishes & $\checkmark$ & & $\checkmark$ & $\checkmark$ & $\checkmark$ & $\checkmark$ & \\
\hline $\begin{array}{l}\text { E12. Furnishings, equipment } \\
\text { and built-ins }\end{array}$ & & & $\checkmark$ & $\checkmark$ & $\checkmark$ & $\checkmark$ & \\
\hline $\begin{array}{l}\text { E13. Window treatment } \\
\text { considerations }\end{array}$ & & & & & $\checkmark$ & $\checkmark$ & \\
\hline F2. Architectural design & $\checkmark$ & & $\checkmark$ & $\checkmark$ & $\checkmark$ & $\checkmark$ & \\
\hline F3. Structural design & & & & $\checkmark$ & $\checkmark$ & $\checkmark$ & \\
\hline
\end{tabular}

Sustainable Sites: Element D4 expresses that projects must be implemented to comply with local regulations, which support project planners to sustainably plan and design the construction site. A previous study discovered that Category D (Site information) tended to invest a significant effort in green projects [14]. Elements E2 and E3 assist project planners to assign the area for bicycle storage. Also, Element E2 helps project planners regarding parking areas for fuel-efficient vehicles and refueling stations for electric vehicles. These relate to the analytical results from the past studies that Category E (Building programing) was discovered as one of the major points in achieving sustainable construction projects $[14,18]$. Element F2 provides the planning for the architectural design process supporting project planners to reduce the impact of high temperature due to the urban heat island problem [18]. These elements were intensively focused on in the green projects because they earn a higher number of credits on aspects of the sustainable site for LEED certification [9]. 
Water Efficiency: As Elements E2 and E3 are related with the design planning process, they definitely support project planners to efficiently allocate water usage in the buildings [26]. For Elements E2 and E3, the analytical results of the past study also confirmed the significance of those elements, as mentioned in [14], that investigated the pre-project planning effort of green building projects in the Republic of Korea. These two elements could play important roles in facilitating the projects to achieve water efficiency credits $[9,26]$.

Energy and Atmosphere: Element E10 assists project planners in designing interior and exterior finishes to optimize the building energy performance and therefore minimize total energy usage [18]. Element E12 promotes an effective plan for designing the furnishing, equipment, and built-ins by incorporating the concept of renewable energy into the design process. Similarly, Element F2 motivates an inclusion of project building energy usage minimization into the architectural design process. The previous studies also mentioned these elements as major success keys to fulfilling the energy-and-atmosphere LEED requirements $[9,18]$.

Material and Resources: Elements E10, E12, F2, and F3 assist project planners in selecting materials and resources under the concept of renewable and recyclable materials. They encourage project planners to sustainably manage materials and resources to generate the lowest amount of construction waste. The importance of these elements was acknowledged in the literature with a significant effort invested into Categories $\mathrm{E}$ and $\mathrm{F}$ in implementing sustainable construction $[14,18]$. Furthermore, it is important to support LEED by selecting the construction materials from the area near the construction site to reduce fuel consumption from material delivery activities [9].

Indoor Environmental Quality: Elements E2 and E3 suggest that project planners avoid having a smoking area during the process of area allocation, to provide air quality and ventilation control in buildings [18]. However, they may provide a smoking area if required under the air pollutant control area [9]. Elements E10, E12, F2, and F3 contribute to a selection of materials with a low emission of dangerous gases, such as chlorine, carbon dioxide, and propane. The construction materials associated with adhesives, sealants, paints, coatings, carpets, composite wood, and laminate adhesives have to be carefully selected [26]. Similarly, Element E13 notes the importance of utilizing proper types of windows in buildings, which help in controlling daylight and air ventilation [18].

Innovation in Design: All nine elements summarized in Table 1 were recognized with the need for proper participation from all parties over the total project period [18]. A certified project is required to have at least one LEED accredited professional to earn the bonus point from innovation in the design section [9].

Regional Priority: For the project samples, their design had to consider water conservation. Elements $\mathrm{E} 2$ and $\mathrm{E} 3$ are the basic procedures helping the projects to accomplish the LEED regional priority credit [9, 26].

\section{(2) Renovation project}

This part identifies six different elements of the planning factors implemented in green and non-green renovation projects. The correlations between the elements and LEED requirements are summarized in Table 2, with their explanations given in the following paragraphs.

Sustainable Sites: Element D5 assists project planners in taking action toward environmental assessment, which facilitates practitioners to evaluate the impact of the renovation of building projects [18]. As existing projects sometimes highly impact areas, the projects should therefore intensively assess the impact of construction on the natural environment [26], encouraging practitioners to earn credits for sustainable sites $[9,26]$.

Water Efficiency: Element G3 motivates project planners to integrate innovative wastewater technologies into the design process with rigorous equipment utility requirements [18]. For example, project planners can decide to use rainwater for water supply [9]. The past studies confirmed the contribution of this element in helping project planners to wisely select efficient equipment for the buildings to reduce water usage in renovation projects $[18,26]$.

Energy and Atmosphere: Element E12 requires project planners to regard the design process of furnishing, equipment, and built-ins under the renewable energy concept. Elements F4 and G3 emphasize the mechanical design, requiring project teams to incorporate the concepts of CFC reduction in HVAC, energy optimization, ozone protection, and good practice commissioning into the process. Additionally, Element G3 aids project planners to consider how the energy used for building equipment can be renewed $[18,26]$. The outdated mechanical system generally utilizes a non-green mechanism that needs to be revamped. The previous study confirmed the focuses of these elements on the renovation of the inefficient mechanical system in buildings [18]. 
Material and Resources: Element E12 facilitates project planners to underline where resources and materials are selected. Construction materials and resources should be recycled from the old structures as much as possible to reduce material waste $[14,27]$. Renovation projects are required to be concerned with the utilization of recycled materials and resources. Because existing buildings have old materials and resources, project planners can decide to bring back those resources for reuse in the building $[8,26]$.

Table 2. Matching Results with the LEED Requirements for Renovation Projects.

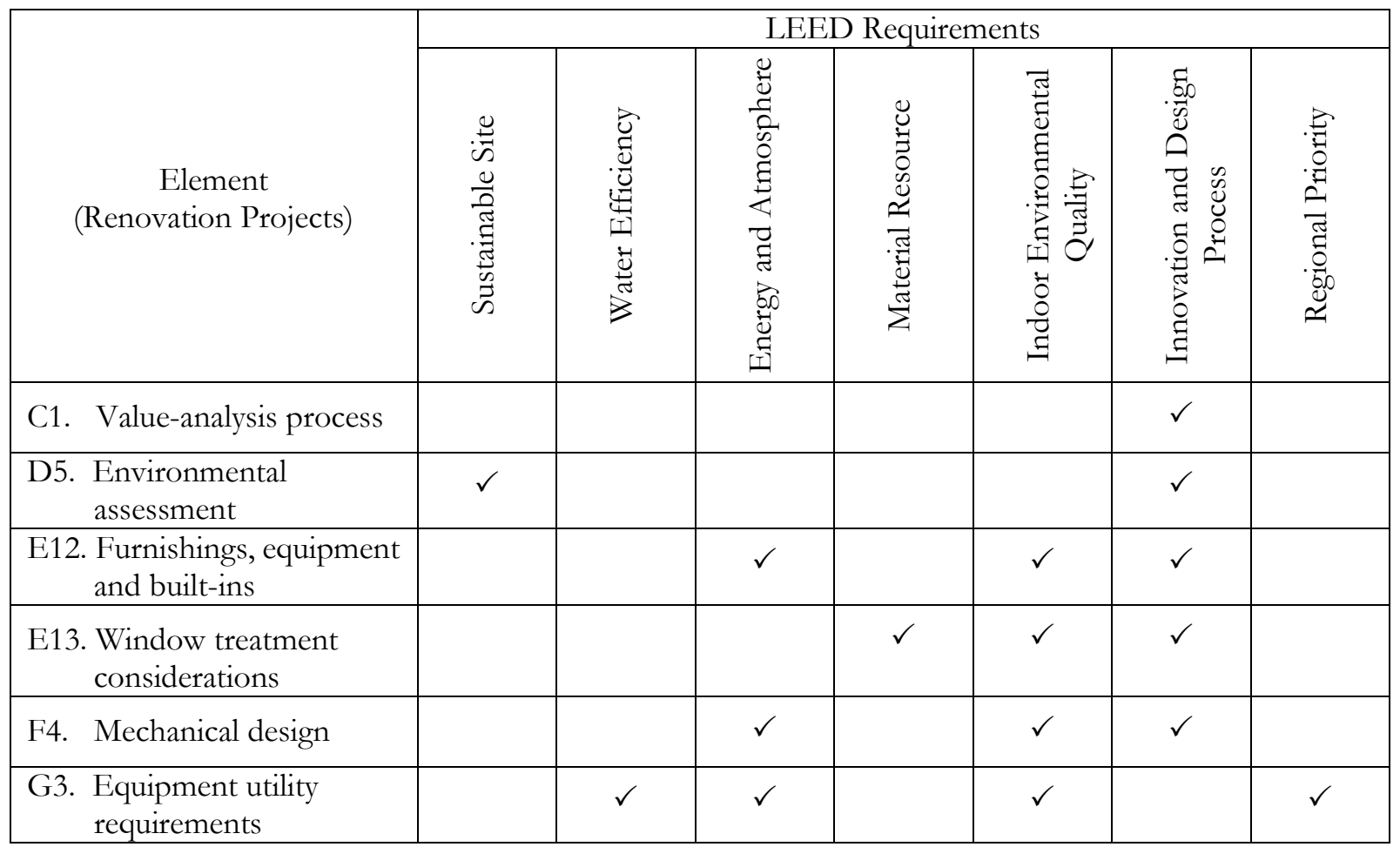

Indoor Environmental Quality: To improve the building air quality, the previous study suggested that project planners focus on Elements E12, E13, F4, and G3 [18]. Element E12 supports the selection of materials with a low harmful-gas emission used in adhesives, sealants, paints, coatings, carpets, composite wood, and laminate adhesives of the buildings. Element E13 introduces the selection of windows for proper control of daylight ventilation. Because old buildings sometimes use materials with a high emission of dangerous gases, those renovating the buildings should therefore carefully design and plan to select suitable materials $[17,18]$. Elements F4 and G3 support the project team to consider the concept of $\mathrm{CO}_{2}$ monitoring and ventilation effectiveness during the mechanical system and equipment utility design [18]. The LEED requirement recommends two informative standards: the ASHRAE standard 62.1-2007 section 4-7 and ASHARE 62.1-2007 subsection 5.1 to be complied for the design process [9, 26].

Innovation in Design: Elements C1, D5, E12, E13, and F4 emphasize who would be the key participants involved in the design process. The LEED standard suggests having at least one LEEDaccredited professional to gain the bonus point from the criterion of innovation in design $[18,26]$.

Regional Priority: Element G3 introduces planning for the mechanical design to properly allocate water resources for the mechanical equipment and system utilization. This assists the projects in obtaining the credit under regional priority [26].

It is noteworthy that Element $\mathrm{C} 1$ reveals a lower planning effort in green than conventional projects. The sustainable projects typically focus on the natural environment production rather than the cost and schedule control [26]. Therefore, the process of value analysis in Element C1, which directly affects the project cost and time, can be less emphasized $[17,28]$. The previous research works mentioned that most sustainable projects are confronted with cost and schedule overruns [14]. This provides major evidence confirming less attention of project planners to Element $\mathrm{C} 1$ for sustainable projects.

The findings from both new and renovation projects were further compared and summarized. They presented that most of their different planning factors were related to the design process, especially for the 
concept of energy conservation, which is the core under the implementation of sustainable construction projects. For example, Elements E12 (Furnishings, equipment and built-ins) and E13 (Window treatment considerations) for new green projects invested less effort than renovation green projects, indicating that renovation projects were more concerned with these two aspects. The relevant information mentioned that most of the renovation projects require a planning stage with a higher consideration of available material resources and equipment. Furthermore, Element E12 facilitates the projects to succeed with a credit point for many LEED requirements, such as energy and atmosphere, material and resources, and indoor environmental quality $[9,26]$.

Implementing the green concept into the project needs an effective pre-project planning effort. Its advantages to each party involved in sustainable projects can be recognized from the following statements. First, the project owners will realize which additional aspects could be implemented during the pre-project planning process. Owners can further apply the results to preliminarily determine the project budget and project duration required for accomplishing sustainable construction projects. Second, the project planners can use the results as the guideline in initiating the project plan. The planning team does not need much emphasis on all planning factors, but only to intensively consider the major planning factors that are necessary for planning sustainable projects. Also, the findings could aid the planning team to prioritize tasks [29] and save time for project planning. Similarly, designers and contractors can direct their main focus and emphasize the major requirements of the projects [30].

Even though different planning factors are discovered, the projects need strong participation from all parties. Every single party should keep contacting each other to completely perceive which sensitive aspects need to be more carefully managed during project implementation. Also, the owner's requirements should be addressed as much as possible by helping all stakeholders to clearly understand the project scope and concerns.

\section{Conclusions}

This paper investigated pre-project planning efforts for green and conventional projects in Thailand. The data were gathered from 42 building projects ( 24 new-constructed projects and 18 renovation projects). The analysis was separated into two sections: new projects and renovation projects. First, this study compared the pre-project planning efforts, discovering that green projects require more planning effort than conventional projects. Second, the different planning factors were determined to acknowledge the major planning factors, which are required for green building construction projects. All analyses were done using the independent ttest. This study revealed the current status and performance of green building construction in Thailand, which are different from the conventional project construction. The findings reinforce the body of knowledge and provide fundamental knowledge to assist practitioners in sustainable construction projects. Also, they acknowledge the associated parties (project owner, project planners, designers, and contractors) in green building construction projects need to intensively plan which aspects should be closely regarded in the preproject planning process. Additionally, the findings can help practitioners without the knowledge, skills, and experience to increase their productivity to promote sustainable construction projects.

However, this paper could be improved to make a greater contribution and to enhance the current body of knowledge. First, the number of samples should be increased to strengthen the analytical results and discover other important aspects. The recommendation was proposed in case more green certified projects are constructed in the near future and are able to be accessible for data collection. Moreover, this paper focused only on the investigation of planning effort in the current green construction industry in Thailand. Therefore, the results can be improved by adding a further practical contribution on the impacts of planning factors on cost and schedule performance of the projects, as they still have not been fully investigated for green building construction in Thailand.

\section{Acknowledgement}

This research is supported in part by the Graduate Program Scholarship from the Graduate School, Kasetsart University. Any opinions, findings, and recommendations written in this paper are those of the authors and do not necessarily reflect any opinions of the funding agency. 


\section{References}

[1] J. R. Fraenkel, N. E. Wallen, and H. H. Hyun, How to Design and Evaluate Research in Education. New York: McGraw-Hill, 1993, vol. 7.

[2] L. Pérez-Lombard, J. Ortiz, and C. Pout, "A review on buildings energy consumption information," Energy and Buildings, vol. 40, no. 3, pp. 394-398, 2008. [Online]. Available: https://doi.org/10.1016/j.enbuild.2007.03.007

[3] Word Business Council for Sustainable Development (WBCSD), Energy Efficiency in BuildingsTransforming the Market. Geneva, 2009.

[4] N. Yamtraipat, J. Khedari, J. Hirunlabh, and J. Kunchornrat, "Assessment of Thailand indoor set-point impact on energy consumption and environment," Energy Policy, vol. 34, no. 7, pp. 765-770, 2006. [Online]. Available: https://doi.org/10.1016/j.enpol.2004.07.009

[5] I. Sartori and A. G. Hestnes, "Energy use in the life cycle of conventional and low-energy buildings: A review article," Energy and Buildings, vol. 39, no. 3, pp. 249-257, 2007. [Online]. Available: https://doi.org/10.1016/j.enbuild.2006.07.001

[6] L. Gustavsson and A. Joelsson, "Life cycle primary energy analysis of residential buildings," Energy and Buildings, vol. 42, no. 2, pp. 210-220, 2010. [Online]. Available: https://doi.org/10.1016/j.enbuild.2009.08.017

[7] A. S. Goudie, Human Impact on the Natural Environment. John Wiley \& Sons, 2018.

[8] D. French, "Developing states and international environmental law: The importance of differentiated responsibilities," International \& Comparative Law Quarterly, vol. 49, no. 1, pp. 35-60, 2000. [Online].

Available: https://doi.org/10.1017/S0020589300063958

[9] U.S. Green Building Council, LEED for New Construction. 2007. [Online]. Available: https://www.usgbc.org/Docs/Archive/General/Docs2952.pdf.

[10] A. Nalewaik and V. Venters, "Cost benefits of building green," IEEE Engineering Management Review, vol. 38, no. 2, pp. 77-87, 2010. [Online]. Available: https://www.researchgate.net/profile/ Ayman_Mosallam/publication/282317298_Energy_Efficient_Environmentally_Compatible_Civil_In frastructure_Systems/data/560b863d08ae840a08d6a295/Energy-Efficient-EnvironmentallyCompatible-Civil-Infrastructure-Systems.pdf\#page $=982$.

[11] S. Schoeffler, R. D. Buzzell, and D. F. J. H. B. R. Heany, "Impact of strategic planning on profit performance," Harvard Business Review, vol. 52, no. 2, 1974. [Online]. Available: https://books.google.co.th/books?hl=en\&lr=\&id=MEUrDwAAQBAJ\&oi=fnd\&pg=PT104\&dq=I mpact + of + strategic + planning + on + profit + performance $+\& o t s=c d B p d p N Q m 3 \& s i g=$ nk $76 \mathrm{fBHbWK}$ h38FKZs7byYaA6iQc\&redir_esc=y\#v=onepage\&q $=$ Impact $\% 20 \mathrm{of} \% 20$ strategic $\% 20$ planning $\% 20$ on $\% 20$ profit $\% 20$ performance\& $\mathrm{f}=$ false

[12] C. S. Cho and E. Gibson, "Development of a project definition rating index (PDRI) for general building projects," in Construction Congress VI: Building Together for a Better Tomorrow in an Increasingly Complex World, 2000, pp. 343-352. [Online]. Available: 10.1061/40475(278)38

[13] C. S. Cho and G. E. Gibson, Jr., "Building project scope definition using project definition rating index," Journal of Architectural Engineering, vol. 7, no. 4, pp. 115-125, 2001. [Online]. Available: https://doi.org/10.1061/(ASCE)1076-0431(2001)7:4(115)

[14] Y. Kang, C. Kim, H. Son, S. Lee, and C. Limsawasd, "Comparison of preproject planning for green and conventional buildings," Journal of Construction Engineering and Management, vol. 139, no. 11, p. 04013018, 2013. [Online]. Available: https://doi.org/10.1061/(ASCE)CO.1943-7862.0000760

[15] H. Son and C. Kim, "Early prediction of the performance of green building projects using pre-project planning variables: Data mining approaches," Journal of Cleaner Production, vol. 109, pp. 144-151, 2015. [Online]. Available: https://doi.org/10.1016/j.jclepro.2014.08.071

[16] M. E. Bayraktar and C. R. Owens, "LEED implementation guide for construction practitioners," Journal of Architectural Engineering, vol. 16, no. 3, pp. 85-93, 2009. [Online]. Available: https://doi.org/10.1061/(ASCE)AE.1943-5568.0000013

[17] K. R. Bunz, G. P. Henze, and D. K. Tiller, "Survey of sustainable building design practices in North America, Europe, and Asia," Journal of Architectural Engineering, vol. 12, no. 1, pp. 33-62, 2006. [Online]. Available: https://doi.org/10.1061/(ASCE)1076-0431(2006)12:1(33) 
[18] G. Weerasinghe, K. Soundararajan, and J. Ruwanpura, "LEED-PDRI Framework for pre-project planning of sustainable building projects," Journal of Green Building, vol. 2, no. 3, pp. 123-143, 2007. [Online]. Available: https://doi.org/10.3992/jgb.2.3.123

[19] Construction Industry Institute (CII), "Project definition rating index: Building projects," Univ. of Texas, Austin, TX, 2008.

[20] E. McColl, "Cognitive interviewing. A tool for improving questionnaire design," Quality of Life Research, vol. 15, no. 3, pp. 571-573, 2006. [Online]. Available: https://doi.org/10.1007/s11136-005-5263-8

[21] I. Brace, Questionnaire Desing: How to Plan, Structure and Write Survey Material for Effective Market Research, 2nd ed. London \& Philadelphia: Kogan Page, 2008.

[22] L. B. Christensen, B. Johnson, and L. A. Turner, Research Methods, Design, and Analysis. 2011.

[23] N. A. Weiss, "Strategies for using technologies in introductory statistics courses," Journal of Statistical Planning and Inference, vol. 78, no. 1-2, pp. 101-110, 1999. [Online]. Available: https://doi.org/10.1016/S0378-3758(98)00209-2

[24] G. Byrne, "A statistical primer: Understanding descriptive and inferential statistics," Evidence Based Library and Information Practice, vol. 2, no. 1, pp. 32-47, 2007. [Online]. Available: https://doi.org/10.18438/B8FW2H

[25] D. S. Moore and S. Kirkland, The Basic Practice of Statistics. New York: WH Freeman, 2007, vol. 2.

[26] U.S. Green Building Council, LEED 2009 for New Construction and Major Renovations. Washington, DC, 2009.

[27] T. M. Swe, P. Jongvivatsakul, and W. Pansuk, "Properties of pervious concrete aiming for LEED green building rating system credits," Engineering Journal, vol. 20, no. 2, pp. 61-72, 2016. [Online]. Available: https://doi.org/10.4186/ej.2016.20.2.61

[28] W. K. Chong, S. Kumar, C. T. Haas, S. M. Beheiry, L. Coplen, and M. Oey, "Understanding and interpreting baseline perceptions of sustainability in construction among civil engineers in the United States," Journal of Management in Engineering, vol. 25, no. 3, pp. 143-154, 2009. [Online]. Available: https://doi.org/10.1061/(ASCE)0742-597X(2009)25:3(143)

[29] N. Sooksil and V. Benjaoran, "The relative factors shaping construction workers' behaviors and leading to accidents," Engineering Journal, vol. 21, no. 5, pp. 257-271, 2017. [Online]. Available: https://doi.org/10.4186/ej.2017.21.5.257

[30] G. Kats, Green Building Costs and Financial Benefits. Boston, MA: Massachusetts Technology Collaborative, 2003. [Online]. Available: http://staging.community-wealth.org/sites/clone.communitywealth.org/files/downloads/paper-kats.pdf. 